\title{
Differential effect of Hurricane Sandy exposure on PTSD symptom severity: comparison of community members and responders
}

\author{
Adam Gonzalez (D) , 1,2 Rehana Rasul, 2,3,4 Lucero Molina, ${ }^{1,2}$ Samantha Schneider, ${ }^{2,5}$ \\ Kristin Bevilacqua, ${ }^{2,3}$ Evelyn J Bromet, ${ }^{1}$ Benjamin J Luft, ${ }^{6}$ Emanuela Taioli, ${ }^{2,7}$ \\ Rebecca Schwartz $2,5,7,8$
}

\begin{abstract}
- Additional material is published online only. To view, please visit the journal online (http://dx.doi.org/10.1136/ oemed-2019-105957).
\end{abstract}

For numbered affiliations see end of article.

\section{Correspondence to} Dr Adam Gonzalez, Psychiatry \& Behavioral Health, SUNY Stony Brook, Stony Brook, NY 11794 USA;

adam.gonzalez@stonybrook. edu

Received 14 May 2019 Revised 13 September 2019 Accepted 25 September 2019 Published Online First 14 October 2019

\section{ABSTRACT}

Objectives To evaluate whether the association between Hurricane Sandy exposures and post-traumatic stress disorder (PTSD) symptom severity was greater for exposed community members compared with responders. Methods Data were analysed from three existing studies with similar methodologies ( $\mathrm{N}=1648)$ : two community studies, Leaders in Gathering Hope Together $(n=531)$ and Project Restoration $(n=763) ;$ and the Sandy/World Trade Center Responders Study $(n=354)$. Sandy-related PTSD symptoms were measured using the PTSD checklist-specific traumatic event and dichotomised as elevated $(\geq 30)$ versus low/no (<30) PTSD symptoms. Sandy exposures were measured with a summed checklist. Multivariable logistic regression was performed to evaluate the differential effect of exposures on PTSD by responder status, adjusting for demographics and time elapsed since Sandy.

Results Responders were somewhat older ( 50.5 years $(S D=8.3)$ vs 45.8 years $(S D=20.0))$, more likely to identify as white $(92.4 \%$ vs $48.1 \%)$ and were male $(90.7 \%$ vs $38.4 \%)$. Responders were less likely to have elevated PTSD symptoms than community members ( $8.6 \%$ vs $31.1 \%$; adjusted $\mathrm{OR}=0.28,95 \% \mathrm{Cl} 0.17$ to 0.46 ). While exposure was significantly related to elevated PTSD status, the effects were similar for responders and community members.

Conclusions Responders appear to be more resilient to PTSD symptoms post-Sandy than community members. Understanding the mechanisms that foster such resilience can inform interventions aimed at populations that are more vulnerable to experiencing PTSD after natural disasters.

\section{INTRODUCTION}

The frequency of natural disasters has increased exponentially in the past 100 years, from 6 reported and recorded events in 1900 to 291 natural disasters in 2000, including disasters such as hurricanes, floods, landslides, wildfires, tsunamis and earthquakes. ${ }^{1}$ Natural disasters often result in damage to the communities of affected areas, as well as to the physical and mental health of individuals exposed to these tragedies. Hurricane Sandy struck the Eastern coastline of the USA on 29 October 2012. At the time, it was the largest Atlantic hurricane to make landfall on the US mainland. Sandy affected 24

\section{Key messages}

What is already known about this subject?

- Individuals exposed to natural disasters, including community members and disaster responders, are at risk of post-traumatic stress disorder (PTSD). Limited research has compared the strength of the relationship between natural disaster exposures and PTSD symptom severity among community members and responders exposed to the same disaster. As natural disasters continue to increase in occurrence, it is important to understand the link between exposures and the severity of PTSD symptoms that community members and responders experience.

What are the new findings?

- Responders and community members reported different types of disaster exposures. The proportion of elevated PTSD symptoms was significantly lower among responders than among community members.

How might this impact on policy or clinical practice in the foreseeable future?

- There may be subpopulations of both responders and community members at risk of mental health difficulties postdisasters. Future postdisaster mental health interventions should focus on vulnerable subpopulations regardless of responder status. It may be possible to provide mental health resilience training to responders to protect health postdisasters.

states, including the entire East Coast, and caused unparalleled damage in the New York metropolitan and Long Island areas. The hurricane and its aftermath resulted in 147 deaths and over 300000 destroyed homes, and millions of individuals were left without electricity for prolonged periods of time. $^{2}$ Moreover, Hurricane Sandy exposed individuals to a variety of environmental toxins as a consequence of floodwaters, the removal of debris and housing reconstruction. Individuals exposed to Sandy and its aftermath were under extraordinary levels of both physical and psychological stress, 
placing them at risk of the development and/or exacerbation of mental and physical health conditions. ${ }^{3}$

Mental health outcomes after natural disasters vary across the exposed population, with subgroups of individuals with severe exposures carrying greater risk than others. ${ }^{4}$ These exposures include loss of loved ones, injury to self and others, destruction of property and evacuation. A large body of trauma ${ }^{56}$ and disaster work, including hurricanes, has found postdisaster increases in post-traumatic stress disorder (PTSD) symptoms and diagnoses in time periods ranging from 5 months to 3 years after the disaster. ${ }^{7-9}$ Hurricane Sandy exposed community members and disaster responders to life endangerment, physical harm, displacement, financial loss and loss of electricity. ${ }^{9-11}$ Previous research has indicated that Sandy-related trauma exposures significantly increased PTSD symptomatology in community members. For instance, elevated PTSD symptoms were prevalent in $23.6 \%$ of 1000 participants from Sandy-affected areas 1 month after the hurricane, ${ }^{12}$ and the degree of Sandy exposure (sum of items endorsed, including loss of property, damaged home, destroyed home, and witnessed and/or sustained an injury from Sandy) was significantly and positively related to PTSD symptoms. ${ }^{13}$ In addition, a cross-sectional survey conducted 6 months after Sandy found $14.5 \%$ of New Jersey shore community members screened positive for PTSD. Moreover, a longitudinal study in the tristate area (New York, New Jersey and Connecticut) reported a 31.2\% PTSD prevalence in individuals who sustained an injury in Sandy-inundated areas and $4.4 \%$ in non-inundated areas 5 months after the disaster. ${ }^{14}$ In addition, high Sandy exposure (assessed by damage to home and possessions, gasoline shortage, prolonged power outage and filing a Federal Emergency Management Agency claim) was associated with a threefold increased likelihood of probable PTSD in World Trade Center (WTC) responders, ${ }^{15}$ suggesting that while community members are more vulnerable to PTSD than responders, exposure severity may not be differentially associated with PTSD symptom onset.

Responders are crucial to efforts during and after disasters. ${ }^{16} 17$ Responders are often the first to arrive to the scene of an accident, work long hours and are exposed to varying degrees of trauma. As such, responders are at elevated risk of PTSD symptoms due to the nature of their work and, in particular, repeated exposures to traumatic events. ${ }^{17-19}$ However, responders may also be resilient to mental health difficulties due to psychosocial factors, such as social support and self-efficacy, ${ }^{20} 21$ and being part of a close community. ${ }^{2022} 23$ Social support in responders is composed of their own personal network and their organisation's network (ie, superiors and coworkers). ${ }^{21}$ Efficacy in responders can be found at an individual level and a collective level. Responders provided with professional training experience to work under hazardous conditions show an increase in self-efficacy. ${ }^{21}$ Similarly, collective self-efficacy, referring to an individual's effort during group tasks and the perceived group's ability to accomplish major tasks, can also serve as a protective factor for responders' health. ${ }^{20}$ Past research has found that responders who experienced occupational trauma reported post-traumatic growth. These changes included positive feelings about helping others in need, contributing to their organisation, accomplishing one's potential and finding meaning in their work efforts. ${ }^{24}$ Several studies have demonstrated resilience to PTSD in responders. ${ }^{25-27}$ For example, a meta-analysis examining estimated PTSD risk among responders and community members exposed to the 11 September 2001 WTC disaster found that responders had a lower risk of probable PTSD compared with community members. ${ }^{26}$ Another study found that a majority of responders to the WTC disaster did not evidence PTSD symptoms $\mathrm{s}^{25}$ and, similarly, research by Bonanno et $\mathrm{al}^{27}$ indicated that, in a sample of 2752 responders, more than half $(51.2 \%)$ were defined as resilient, having either no PTSD symptoms or one symptom.

The current study examined Hurricane Sandy exposures that were experienced by community members and responders participating in three studies conducted in the New York metropolitan area. The aims of this study were to (1) characterise the exposures occurring in community versus responder cohorts and (2) compare the strength of the association between hurricane exposure and PTSD symptom severity in these cohorts. This research will extend the association between trauma exposure and the post-traumatic stress response in responders and community members by examining PTSD symptoms in those affected by Hurricane Sandy. Based on prior research, we predicted that there would be a stronger association between exposure severity and PTSD symptoms among community members compared with responders. The current study extends the literature by examining differences in exposures and PTSD symptom severity between community members and responders exposed to a natural disaster.

\section{METHOD \\ Study samples}

Data from three existing studies, Leaders in Gathering Hope Together (LIGHT), Project Restoration (PR) and the Sandy/ WTC Responders study, were combined for this investigation. All studies were approved by an institutional review board, and all participants provided informed consent for participation.

\section{LIGHT/PR}

Project LIGHT, a federally funded study, included participants from Queens, Staten Island and Nassau and Suffolk Counties (Long Island) between 23 October 2013 and 25 February 2015. PR, a foundation-funded study, used the same survey as LIGHT but included only residents who lived in the Rockaways (Queens, New York) when Hurricane Sandy hit; participants were recruited from 5 June 2014 to 9 August 2016. Further details about study design can be found in Bevilacqua et al. ${ }^{28}$ Of note, both studies used convenience sampling in that interested potential participants approached the research booth at various places, like street fairs, libraries and supermarkets. Exclusion criteria were not speaking English or Spanish, having cognitive impairments that would prevent informed consent, being under 18 years old, or not living in Long Island or New York City during Hurricane Sandy. If eligible, participants completed a selfreport questionnaire and were given $\$ 15$ as incentive. From the original LIGHT/PR cohort $(\mathrm{N}=1665)$, first responders $(\mathrm{n}=51)$ and those who assisted with rescue/recovery during Hurricane Sandy $(n=289)$, or both $(n=33)$ were excluded. The final sample size consisted of 1294 participants.

\section{Sandy/WTC Responders study}

Participants in this federally funded study included responders to the WTC disaster who attended a health monitoring visit at the Stony Brook University WTC Health Programme between 5 September 2013 and 18 December 2014. This centre is the second largest of five clinical centres of excellence established by the Centers for Disease Control and Prevention to provide annual health monitoring and treatment to responders of the WTC disaster. All responders who completed a health monitoring visit the year before Hurricane Sandy were approached 
by study staff during their next health monitoring visit and were invited to participate in a study to assess exposures and health after Hurricane Sandy. Interested participants completed a consent form and a battery of questionnaires assessing exposures to Sandy and mental health symptoms. For the current study, we included only WTC participants who responded, in a volunteer or a paid capacity, to Hurricane Sandy $(n=354)$. The final combined study sample included 1648 participants.

\section{Study variables}

To harmonise data from two existing studies, commonalities between the questionnaires from LIGHT/PR and Sandy/WTC Responder participants were determined and confirmed by all study investigators. All studies used the same PTSD symptom inventory.

\section{Outcome: PTSD symptom severity}

The PTSD checklist-specific version ${ }^{29} \quad$ (range=17-85) is a 17-item self-report measure assessing the severity of Diagnostic and Statistical Manual of Mental Disorders, Fourth Edition, PTSD criterion symptoms. Participants ere asked to rate how bothered they were by problems in the past month 'in relation to Hurricane Sandy' on a scale of ' $1=$ not at all' to ' $5=$ extremely.' The scale items demonstrated good temporal stability, internal consistency, test-retest reliability and convergent validity. ${ }^{30}$ In the total sample (Cronbach's alpha $=0.961$ ) and within responders (Cronbach's alpha $=0.927)$ and community (Cronbach's alpha $=0.960)$ samples, internal consistency was high. A sum score of $\geq 30$ was used to indicate elevated PTSD symptom severity. ${ }^{31}$ If a participant responded to $<14$ items, a PTSD symptom score was not calculated. Symptom scores were imputed for one to three missing items $(n=12)$.

\section{Hurricane exposure}

A hurricane exposure questionnaire was included in each study. The LIGHT/PR exposure tool was developed based on questionnaires administered after Hurricanes Katrina, Gustav and Andrew. ${ }^{32}$ The Sandy/WTC Responder study used a similarly developed exposure tool. ${ }^{34}$ Study authors reviewed each item from each study for comparability. Twenty hurricane exposure items (scored yes/no) were common to each questionnaire (online supplementary appendix 1) and were summed to determine total hurricane exposure due to Hurricane Sandy (range $0-20)$.

\section{Other study variables}

In addition to community versus responder status, the analysis included demographic characteristics (age, gender, race (white/ other), ethnicity (Hispanic/non-Hispanic) and education (high school (HS) or lower/some college education or higher)). Time in months elapsed from Hurricane Sandy to survey completion was also modelled.

\section{Statistical analysis}

Frequency and per cent of categorical variables were compared by responder status. For continuous variables, the mean and SD or the median and IQR were calculated. Differences were assessed using $\chi^{2}$ test or Mann-Whitney rank-sum test for categorical and continuous variables, respectively. To evaluate whether there was a differential effect of hurricane exposure on elevated PTSD symptom severity by responder status, multivariable logistic regression was performed, adjusting for all demographics and time elapsed since Hurricane Sandy. An interaction between responder status and total hurricane exposure was tested and kept in the model if significant. Adjusted ORs (aORs), 95\% CIs and $\mathrm{p}$ values were reported. Significance was reported if the $\mathrm{p}$ value was $<0.05$. For the model, $91.4 \%$ of the participants had complete data. All analyses were conducted using SAS V.9.4.

\section{Sensitivity analysis}

Since the majority of responders were men (90.7\%), we checked the sensitivity of the results to gender by performing the model using data from men only, with the same adjustments except gender, and found similar results. Additionally, we found no evidence of collinearity between gender and responder status (variance inflation factor $(<5)$ ).

\section{RESULTS}

Responders comprised $21.5 \%$ of the combined sample $(\mathrm{n}=1648)$. On average, responders were slightly older $(50.5$ $(\mathrm{SD}=8.3)$ vs 45.8 years $(\mathrm{SD}=20.0))$ than community members (table 1). Additionally, more responders were Caucasian $(92.4 \%$ vs $48.1 \%$ ) and male $(90.7 \%$ vs $38.4 \%)$. Most participants in both groups had at least some college education $(83.4 \%$ of the community and $82.9 \%$ of the responders). The proportion of responders with elevated PTSD was significantly lower than that among community members (8.6\% vs $31.1 \%)$.

The median (IQR) number of hurricane exposures experienced by responders (median 2 (IQR 1-3)) was lower than that of community members (median 3 (IQR 1-5)). Type of hurricane exposure differed between community members and responders (table 2). Community members more frequently reported having a family member whose life was in danger, being unprepared to evacuate or being displaced, having property damage (vehicle loss and flooding) and having difficulty with getting to work, accessing food and unemployment compared with responders. Responders had higher proportions of reporting their life was in danger (31.1\% vs $15.5 \%)$ and witnessing death or injury $(16.7 \%$ vs $3.9 \%)$. They also indicated losing power and not having access to gas more frequently than community members. Elevated PTSD proportions were higher among responders compared with the community among those who reported their life was in danger and if they did not have access to gas or lost power/electricity (figure 1).

When modelling the main effects (table 3 ), being a responder was associated with a $72 \%$ decreased $(\mathrm{aOR}=0.28,95 \% \mathrm{CI} 0.17$ to 0.46 ) of elevated PTSD symptom severity compared with the community sample. The number of hurricane exposures was also significantly associated with elevated PTSD status $(\mathrm{aOR}=1.34$, $95 \%$ CI 1.28 to 1.40 ). However, the interaction effect of total exposures and responder status was not significant, indicating no differential effect of exposure among community versus responder groups.

Several demographic characteristics were also significantly associated with elevated PTSD status, including being non-white versus white, being Hispanic versus non-Hispanic, and lower educational attainment.

\section{DISCUSSION}

The current study sought to examine the types of exposures experienced by responders and community members as a result of Hurricane Sandy and to evaluate whether the association between hurricane exposures and elevated PTSD symptom severity was different for responders compared with community members. Overall, responders were older and more likely to selfidentify as white and male, but had similar levels of educational 
Table 1 Participant characteristics compared by responder status

\begin{tabular}{|c|c|c|c|c|c|}
\hline \multirow[t]{2}{*}{ Characteristic } & \multicolumn{2}{|c|}{ Community members $(n=1294)$} & \multicolumn{2}{|c|}{ Responders $(n=354)$} & \multirow[t]{2}{*}{$P$ value } \\
\hline & $\mathrm{n}$ & $\%$ & $\mathrm{n}$ & $\%$ & \\
\hline Age (years), mean (SD) & 45.8 & 20.0 & 50.5 & 8.3 & $<0.001$ \\
\hline Race & & & & & $<0.001$ \\
\hline White & 612 & 48.1 & 315 & 92.4 & \\
\hline Other & 660 & 51.9 & 26 & 7.6 & \\
\hline Hispanic ethnicity & & & & & $<0.001$ \\
\hline Non-Hispanic & 1034 & 81.3 & 271 & 92.2 & \\
\hline Hispanic & 238 & 18.7 & 23 & 7.8 & \\
\hline Education & & & & & 0.83 \\
\hline High school graduate and lower & 208 & 16.6 & 59 & 17.1 & \\
\hline$\geq$ Some college & 1042 & 83.4 & 286 & 82.9 & \\
\hline Gender & & & & & $<0.001$ \\
\hline Male & 496 & 38.4 & 321 & 90.7 & \\
\hline Female & 796 & 61.6 & 33 & 9.3 & \\
\hline Total hurricane exposure, median (IQR) & 3 & $1-5$ & 2 & $1-3$ & $<0.001$ \\
\hline $\begin{array}{l}\text { Elapsed time between survey and Hurricane } \\
\text { Sandy (months), median (IQR) }\end{array}$ & 22.9 & $17.7-37.1$ & 16.6 & $14.3-19.0$ & $<0.001$ \\
\hline PTSD symptom score, median (IQR) & 23 & $18-34$ & 17 & $17-20$ & $<0.001$ \\
\hline Elevated PTSD & & & & & $<0.001$ \\
\hline Yes & 414 & 32.2 & 30 & 8.6 & \\
\hline No & 872 & 67.8 & 320 & 91.4 & \\
\hline
\end{tabular}

Numbers may not add to total due to missing values in each characteristic. P value from $\chi^{2}$ tests for categorical variables, Mann-Whitney rank-sum test for age, elapsed time between survey and Hurricane Sandy and total hurricane exposure.

PTSD, post-traumatic stress disorder.

attainment as compared with community members. In addition, the proportion of elevated PTSD symptoms was significantly lower among responders than among community members. This finding is consistent with past research focused on a man-made disaster $^{26}$ and extends the literature to trauma exposure as a result of a natural disaster.
Responders and community members tended to experience different types of exposure during Hurricane Sandy. Responders more frequently reported that their lives were in danger or that they witnessed death and injury. Community members more frequently reported having a family member whose life was in danger, being unprepared to evacuate, being displaced, having

Table 2 Hurricane exposure items compared by responder status

\begin{tabular}{|c|c|c|c|c|c|}
\hline \multirow[t]{2}{*}{ Hurricane exposure items } & \multicolumn{2}{|c|}{ Community members $(n=1294)$} & \multicolumn{2}{|c|}{ Responders ( $n=354)$} & \multirow[t]{2}{*}{$P$ value } \\
\hline & n & $\%$ & n & $\%$ & \\
\hline Family member missing & 41 & 3.2 & 1 & 0.3 & 0.002 \\
\hline Friend missing & 46 & 3.6 & 1 & 0.3 & 0.001 \\
\hline Life was in danger & 201 & 15.5 & 110 & 31.1 & $<0.001$ \\
\hline Physically harmed & 40 & 3.1 & 18 & 5.1 & 0.071 \\
\hline Life of family member(s) in danger & 180 & 13.9 & 14 & 4.0 & $<0.001$ \\
\hline Pet missing or dead & 49 & 3.8 & 11 & 3.1 & 0.545 \\
\hline Vehicle loss & 188 & 14.5 & 27 & 7.6 & $<0.001$ \\
\hline Loss of power/electricity & 950 & 73.4 & 309 & 87.3 & $<0.001$ \\
\hline Great difficulty commuting to work/school due to transportation issues/gasoline shortage & 363 & 28.1 & 49 & 13.8 & $<0.001$ \\
\hline Great difficulty accessing food for self/family & 265 & 20.5 & 13 & 3.7 & $<0.001$ \\
\hline Unable to access necessary medical care & 86 & 6.7 & 13 & 3.7 & 0.037 \\
\hline Unable to access gasoline for vehicle & 287 & 22.2 & 219 & 61.9 & $<0.001$ \\
\hline Witnessed death/injury (self or household)/witnessed death/injury (other; eg, neighbour) & 50 & 3.9 & 59 & 16.7 & $<0.001$ \\
\hline Home damaged or destroyed & 416 & 32.2 & 81 & 22.9 & 0.001 \\
\hline
\end{tabular}

Numbers may not add to total due to missing values in each characteristic. P value from Chi-square tests. 


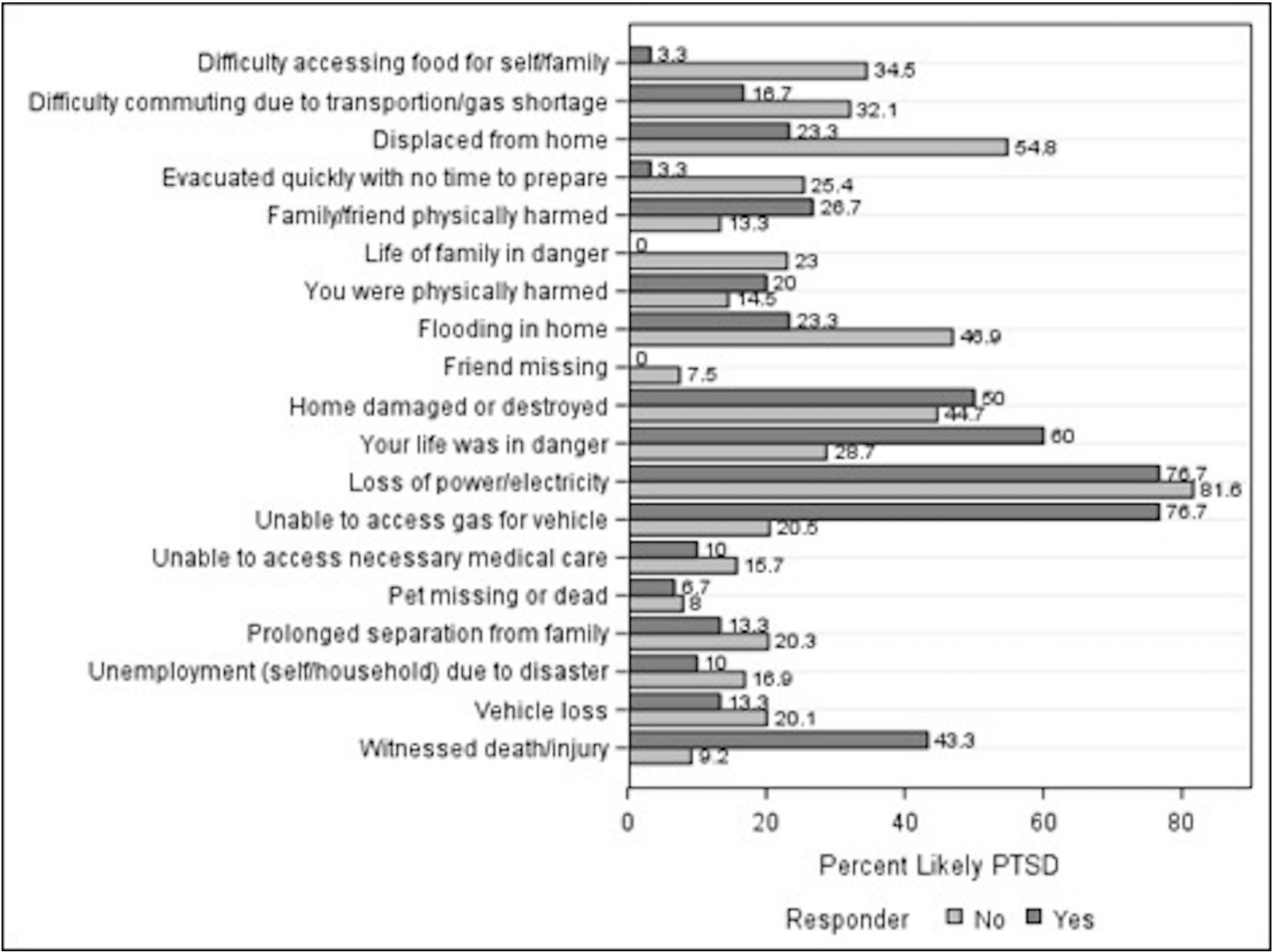

Figure 1 Elevated PTSD among those who experienced individual hurricane exposure items by responder status. PTSD, post-traumatic stress disorder.

property damage and having difficulty getting to work, accessing food and unemployment compared with responders. Unfortunately, it was not possible to separate out whether the hurricane exposure items experienced by a responder were due to their capacity as a responder or from their experience as a member of the general affected community. We can only speculate that rates of certain exposure items were higher or lower due to their professional capacity. For example, responders may have experience with and training in disaster preparedness and thus may be less likely to experience certain hardships during disasters (ie, being unprepared to evacuate and accessing food) and perhaps are more likely than general community members to experience other exposures (ie, lives being in danger, witnessing death and injury). Elevated PTSD proportions were higher among responders compared with the community members, among those who experienced their lives being in danger and among those who did not have access to gas or lost power/electricity (figure 1). Higher Sandy exposure, separately from occupation, consistently remains strongly associated with a greater likelihood of PTSD symptoms, which is supported by previous literature. ${ }^{3}$ It is possible that the type of trauma experienced may confer differential risk for PTSD symptomatology.

Despite the fact that responders had less odds of elevated PTSD in comparison to the community members, the interaction of total hurricane exposure and responder status was not significant. The context in which responders and community members experienced various exposures to Hurricane Sandy may have implications for the relationship between responder status and PTSD. In addition, there are various psychosocial factors that may contribute to responder resilience and serve as protective factors against developing PTSD. For example, previous research indicates that social support and self-efficacy, ${ }^{21}$ as well as feeling part of the community, ${ }^{20} 22$ may promote resilience among responder populations. Responders often have good sources of social support due to the closeness experienced as part of their occupation and tend to have higher self-efficacy related to their drive to serve and protect their community. Past research has shown that responders' sense of community, such as a sense of belonging and an emotional connection with the community, ${ }^{22}$ is associated with greater social support. ${ }^{35}$ Similarly, responders have professional training and experience with working under threatening situations, which has been linked to increased selfefficacy. ${ }^{24} 35$ Other work indicates that having a positive world view is a significant protective factor for responders. ${ }^{36}$ Moreover, research increasingly supports the role of biological factors, such as genetics, epigenetics and neurocircuitry in the experience of resilience. ${ }^{37} 38$ Higher Hurricane Sandy exposure, separately from occupation, consistently remains strongly associated with a greater likelihood of PTSD symptoms, which is supported by previous literature. ${ }^{3}$ Future research may focus on disentangling the differential impacts of occupational exposures versus personal exposures among responder populations on mental health outcomes and how psychosocial and biological factors like social support may moderate this relationship.

Previous studies have found certain subgroups, including ethnic minorities and low-resourced individuals (eg, those without health insurance), to be more vulnerable to the mental health impacts of natural disasters, due in part to barriers to 
Table 3 Multivariable logistic regression analysis of associations between characteristics and elevated PTSD status

\section{PTSD controls}

(n)* PTSD cases $(n)^{*}$ aOR $(95 \% \mathrm{Cl}) \dagger$

\begin{tabular}{|c|c|c|c|}
\hline Variable & & & \\
\hline \multicolumn{4}{|l|}{ Responder status } \\
\hline Responder & 261 & 24 & $0.28(0.17$ to 0.46$)$ \\
\hline $\begin{array}{l}\text { Community } \\
\text { member (ref) }\end{array}$ & 835 & 387 & \\
\hline $\begin{array}{l}\text { Total number of } \\
\text { hurricane exposures }\end{array}$ & $2(1-4)$ & $5(3-7)$ & 1.34 (1.28 to 1.4$)$ \\
\hline \multicolumn{4}{|l|}{ Race } \\
\hline Other & 426 & 227 & 1.97 (1.47 to 2.64$)$ \\
\hline White (ref) & 670 & 184 & \\
\hline \multicolumn{4}{|l|}{ Ethnicity } \\
\hline Hispanic & 153 & 97 & 1.99 (1.4 to 2.83$)$ \\
\hline Non-Hispanic (ref) & 943 & 314 & \\
\hline \multicolumn{4}{|l|}{ Education } \\
\hline $\begin{array}{l}\text { HS graduate and } \\
\text { lower }\end{array}$ & 153 & 100 & 1.79 (1.29 to 2.49$)$ \\
\hline$>$ Some college (ref) & 943 & 311 & \\
\hline Age§ & 46.99 (18.99) & $45.97(16.10)$ & 1.06 (0.8 to 1.39$)$ \\
\hline $\begin{array}{l}\text { Elapsed time between } \\
\text { survey and Hurricane } \\
\text { Sandy } \ddagger\end{array}$ & $\begin{array}{l}19.8 \\
(14.5-27.9)\end{array}$ & $\begin{array}{l}21.7 \\
(18.0-37.1)\end{array}$ & 1 (1 to 1.01$)$ \\
\hline \multicolumn{4}{|l|}{ Gender } \\
\hline Female & 537 & 242 & 1 (0.98 to 1.01$)$ \\
\hline Male (ref) & 559 & 169 & \\
\hline
\end{tabular}

${ }^{*}$ Model used 1509/1648 participants due to missing data.

taOR and $95 \% \mathrm{Cl}$ from the multivariable logistic regression model adjusted for elapsed time between survey and Hurricane Sandy and all demographics shown. ¥Median (IQR) presented instead of number.

$\S$ Mean (SD) presented instead of number.

aOR, adjusted OR; HS, high school; PTSD, post-traumatic stress disorder; ref, reference.

mental healthcare. ${ }^{39}$ In our sample, being non-white or Hispanic and having an HS education or lower were all significantly associated with almost twofold increased odds of elevated PTSD status, regardless of responder status. These findings underscore the importance of focusing on potentially vulnerable populations, such as lower-resourced individuals and ethnic minorities, in the wake of a disaster regardless of their membership in groups that may otherwise exhibit resilience.

\section{Limitations}

Given that this study combined samples from existing studies, the contributions of differences in the study populations and design cannot be evaluated beyond the demographic characteristics adjusted in the analyses. Since all studies were cross-sectional and retrospective, it is not possible to determine causality or to ascertain temporality. The hurricane occurred on 29 October 2012 and the PTSD checklist prompted respondents to answer items based on the last month. Elevated PTSD was based on a cut-off of $\leq 30 .{ }^{31}$ We note that the use of the continuous measure of PTSD symptom severity as an outcome violated assumptions of linearity, and therefore, we dichotomised PTSD. Future studies done closer in time to the disaster would benefit from using diagnostic interview assessments to determine the presence of PTSD diagnoses. In addition, all of the samples were samples of convenience, and the responders, in particular, were presenting for health monitoring. As such, it is possible that there may be biases in reporting in both groups. Future studies might randomly select participants in exposed communities and responder organisations. Given the low frequencies of certain exposures among responders, we were not able to explore whether the effects of individual hurricane exposure items were differentially associated with elevated PTSD by responder status. Last, the current study was not able to account for prior mental health history and treatment and history of trauma exposures. Predisaster psychopathology and trauma history have consistently been identified as important predictors of mental health following exposure to trauma. ${ }^{91540}$

\section{CONCLUSIONS}

The findings of our study have important implications for research and intervention in a postdisaster context. This study extends the literature on the differential impact of trauma exposure on responders and community members exposed to a natural disaster. Though responders appear to be more resilient to mental health difficulties postdisaster, the mechanisms that contribute to that resilience are not well understood. Future research may seek to understand the psychosocial factors that contribute to such resilience, as compared with a non-responder population. Notably, responders who are also part of potentially vulnerable subpopulations may be at a greater risk of mental health difficulties than those who are not. Future postdisaster mental health interventions should focus on vulnerable subpopulations regardless of responder status.

\section{Author affiliations}

${ }^{1}$ Psychiatry and Behavioral Health, SUNY Stony Brook, Stony Brook, New York, USA ${ }^{2}$ Center for Disaster Health, Trauma, and Resilience, Mount Sinai, SUNY Stony Brook, Northwell Health, New York City, New York, USA

${ }^{3}$ Occupational Medicine, Epidemiology and Prevention, Northwell Health, Great Neck, New York, USA

${ }^{4}$ Biostatistics, Feinstein Insitute for Medical Research at Northwell Health, Great Neck, New York, USA

${ }^{5}$ Department of Occupational Medicine, Epidemiology and Prevention, Northwell Health, Great Neck, New York, USA

${ }^{6}$ Medicine, SUNY Stony Brook, Stony Brook, New York, USA

${ }^{7}$ Population Health Science and Policy, Icahn School of Medicine at Mount Sinai, New York City, New York, USA

${ }^{8}$ Occupational Medicine Epidemiology and Prevention, Zucker School of Medicine at Hofstra/Northwell, Great Neck, New York, USA

Correction notice This article has been corrected since it published Online First.

Contributors AG led the Sandy/WTC Responders study and co-led the development of the research questions for the current study. He also contributed to the writing of the introduction, methods and discussion sections and edited the final manuscript. RR led the data analytic plan and statistical analyses. She also contributed to the writing of the methods and results section, and editing of the final manuscript. LM contributed to writing the introduction section and provided edits to the final manuscript. SS contributed to writing the methods and discussions sections and edited the final manuscript. KB contributed to writing the discussion section and edited the final manuscript. EJB contributed to the design of the Sandy/WTC Responders study and edited the final manuscript. BJL contributed to the design of the Sandy/WTC Responders study and edited the final manuscript. ET led the Project Leaders in Gathering Hope Together study and edited the final manuscript. RS led the Project Restoration study and co-led the development of the research questions for the current study. She edited the final manuscript. She contributed to the writing of the methods and discussion sections and edited the final manuscript.

Funding This study was funded by the Department of Health and Human Services Office of the Assistant Secretary for Preparedness and Response \#EP-HIT-14-0020) and the Centers for Disease Control and Prevention (\#U01-TP000573-01).

Competing interests None declared.

Patient consent for publication Not required.

Provenance and peer review Not commissioned; externally peer reviewed. Data availability statement Data are available upon reasonable request.

ORCID iD

Adam Gonzalez http://orcid.org/0000-0002-8487-6282 


\section{REFERENCES}

1 Ritchie H, Roser M. Natural disasters, 2018. Available: https://ourworldindata.org/ natural-disasters [Accessed 8 Nov 2018].

2 Blake ES, Kimberlain TB, Berg RJ, et al. Tropical cyclone report: Hurricane sandy. National Hurricane Center 2013;12:1-10.

3 Schwartz RM, Gillezeau CN, Liu B, et al. Longitudinal impact of Hurricane sandy exposure on mental health symptoms. Int J Environ Res Public Health 2017;14:957.

4 Fergusson DM, Horwood LJ, Boden JM, et al. Impact of a major disaster on the mental health of a well-studied cohort. JAMA Psychiatry 2014;71:1025-31.

5 Yehuda R. Post-Traumatic stress disorder. N Engl J Med 2002;346:108-14.

6 Breslau N. Epidemiologic studies of trauma, posttraumatic stress disorder, and other psychiatric disorders. Can J Psychiatry 2002;47:923-9.

7 Galea S, Brewin CR, Gruber M, et al. Exposure to hurricane-related stressors and mental illness after Hurricane Katrina. Arch Gen Psychiatry 2007;64:1427-34.

8 Galea S, Nandi A, Vlahov D. The epidemiology of post-traumatic stress disorder after disasters. Epidemiol Rev 2005:27:78-91.

9 Schwartz, PhD RM, Sison, PhD C, Kerath, MS SM, et al. The impact of Hurricane sandy on the mental health of new York area residents. Am J Disaster Med 2015;10:339-46 https://doi.org/

10 Bromet EJ, Atwoli L, Kawakami N, et al. Post-Traumatic stress disorder associated with natural and human-made disasters in the world mental health surveys. Psychol Med 2017;47:227-41 https://doi.org/

11 Schwartz RM, Rasul R, Kerath SM, et al. Displacement during Hurricane sandy: the impact on mental health. J Emerg Manag 2018;16:17-27.

12 Palgi Y, Shrira A, Hamama-Raz Y, et al. Not so close but still extremely loud: recollection of the world Trade center terror attack and previous hurricanes moderates the association between exposure to Hurricane sandy and posttraumatic stress symptoms. Compr Psychiatry 2014;55:807-12.

13 Shrira A, Palgi Y, Hamama-Raz Y, et al. Previous exposure to the world Trade center terrorist attack and posttraumatic symptoms among older adults following Hurricane sandy. Psychiatry 2014;77:374-85

14 Caramanica Ket al. Posttraumatic stress disorder after Hurricane sandy among persons exposed to the 9/11 disaster. Int J Emerg Ment Health 2015;17.

15 Bromet EJ, Clouston S, Gonzalez A, et al. Hurricane sandy exposure and the mental health of World Trade center responders. J Trauma Stress 2017;30:107-14 https://doi. org/

16 Berger W, Coutinho ESF, Figueira I, et al. Rescuers at risk: a systematic review and meta-regression analysis of the worldwide current prevalence and correlates of PTSD in rescue workers. Soc Psychiatry Psychiatr Epidemiol 2012;47:1001-11.

17 Morren M, Yzermans CJ, van Nispen RMA, et al. The health of volunteer firefighters three years after a technological disaster. J Occup Health 2005;47:523-32.

18 Benedek DM, Fullerton C, Ursano RJ. First responders: mental health consequences of natural and Human-Made disasters for public health and public safety workers. Annu Rev Public Health 2007;28:55-68.

19 Breslau N, Peterson EL, Schultz LR. A second look at prior trauma and the posttraumatic stress disorder effects of subsequent trauma: a prospective epidemiological study. Arch Gen Psychiatry 2008:65:431-7.

20 Pietrantoni L, Prati G. Resilience among first responders. Afr Health Sci 2008;8 Suppl 1:S14-20.
21 Regehr C, Hill J, Knott T, et al. Social support, self-efficacy and trauma in new recruits and experienced firefighters. Stress and Health 2003;19:189-93.

22 McMillan DW, Chavis DM. Sense of community: a definition and theory. J Community Psychol 1986;14:6-23.

23 Cowman SE, Ferrari JR, Liao-Troth M. Mediating effects of social support on firefighters' sense of community and perceptions of care. J Community Psychol 2004;32:121-6.

24 Shakespeare-Finch JE, Smith SG, Gow KM, et al. The prevalence of post-traumatic growth in emergency ambulance personnel. Traumatology 2003;9:58-71.

25 Schetter CD, Dolbier C. Resilience in the context of chronic stress and health in adults. Soc Personal Psychol Compass 2011;5:634-52

26 Liu B, Tarigan LH, Bromet EJ, et al. World Trade center disaster exposure-related probable posttraumatic stress disorder among responders and civilians: a metaanalysis. PLoS One 2014;9:e101491.

27 Bonanno GA, Galea S, Bucciarelli A, et al. Psychological resilience after disaster: new York City in the aftermath of the September 11th terrorist attack. Psycho/ SCi 2006;17:181-6.

28 Bevilacqua K, Schneider S, Rasul R, et al. Engagement in linkage to mental health care program in the Rockaways after Hurricane sandy. J. Community Psychol 2018:1-14.

29 Weathers F, Litz B, Herman D, et al. The PTSD Checklist (PCL): Reliability, Validity, and Diagnostic Utility. San Antonio, TX: Paper presented at the Annual Convention of the International Society for Traumatic Stress Studies, 1993.

30 Wilkins KC, Lang AJ, Norman SB. Synthesis of the psychometric properties of the PTSD checklist (PCL) military, civilian, and specific versions. Depress Anxiety 2011;28:596-606.

31 National center for posttraumatic stress disorder. Using the PTSD checklist for DSM_IV (PCL), 2014. Available: https://www.ptsd.va.gov/professional/assessment/documents/ PCL_handoutDSM4.pdf

32 Harville EW, Xiong X, Smith BW, et al. Combined effects of Hurricane Katrina and Hurricane Gustav on the mental health of mothers of small children. J Psychiatr Ment Health Nurs 2011;18:288-96 https://doi.org/

33 Norris FH, Perilla JL, Riad JK, et al. Stability and change in stress, resources, and psychological distress following natural disaster: findings from Hurricane Andrew. Anxiety, Stress \& Coping 1999;12:363-96 https://doi.org/

34 Brackbill RM, Caramanica K, Maliniak M, et al. Nonfatal injuries 1 week after hurricane sandy-New York city metropolitan area, October 2012. MMWR. Morbidity and Mortality Weekly Report 2014;63.

35 North CS, Tivis L, McMillen JC, et al. Psychiatric disorders in rescue workers after the Oklahoma City bombing. American Journal of Psychiatry 2002:159:857-9.

36 Yuan C, Wang Z, Inslicht SS, et al. Protective factors for posttraumatic stress disorde symptoms in a prospective study of police officers. Psychiatry Res 2011;188:45-50.

37 Feder A, Nestler EJ, Charney DS. Psychobiology and molecular genetics of resilience. Nat Rev Neurosci 2009;10:446-57.

38 Kuan P-F, Waszczuk MA, Kotov R, et al. An epigenome-wide DNA methylation study of PTSD and depression in world Trade center responders. Trans/ Psychiatry 2017;7:e1158

39 Wang Z, Inslicht SS, Metzler TJ, et al. A prospective study of predictors of depression symptoms in police. Psychiatry Res 2010;175:211-6.

40 Brewin CR, Andrews B, Valentine JD. Meta-Analysis of risk factors for posttraumatic stress disorder in trauma-exposed adults. J Consult Clin Psychol 2000:68:748-66. 